\title{
Desempenho e balanço de nitrogênio de suínos em terminação que receberam dieta restrita ou à vontade, com diferentes teores de lisina
}

\author{
[Performance and nitrogen balance of finish barrows receiving restricted or ad libitum \\ diets, with different amount of lysine] \\ E.C. Almeida ${ }^{1}$, M.G. Zangeronimo ${ }^{2}$, E.T. Fialho ${ }^{2}$, V.S. Cantarelli ${ }^{2}$, R.C. Wolp ${ }^{3}$, V.V. Rodrigues ${ }^{4}$ \\ ${ }^{1}$ Universidade Federal de Goiás - UFG \\ ${ }^{2}$ Universidade Federal de Lavras - UFLA \\ Caixa Postal 3037 \\ 37200-000 - Lavras, MG - Brasil \\ ${ }^{3}$ Zootecnista autônomo \\ ${ }^{4}$ Universidade Federal de Viçosa
}

\begin{abstract}
RESUMO
Dois experimentos foram realizados para avaliar a influência de duas porcentagens de lisina associada à restrição alimentar sobre o desempenho e balanço de nitrogênio de suínos em terminação. No experimento I, foram utilizados 48 suínos machos castrados, com média de peso de $76,2 \pm 2,3 \mathrm{~kg}$, distribuídos em delineamento em blocos ao acaso, em esquema fatorial 2x2 (duas porcentagens de lisina total - normal ou com $30 \%$ a mais - e duas formas de arraçoamento - à vontade ou com restrição). Com 28 dias, a porcentagem de inclusão de lisina não influenciou o ganho de peso, mas a porcentagem mais alta resultou em menor consumo e melhor conversão alimentar. A restrição alimentar diminuiu o ganho de peso sem afetar a conversão alimentar. No experimento II, 24 suínos machos castrados, com média de peso de $74,1 \pm 2,5 \mathrm{~kg}$, foram alojados em gaiolas de metabolismo para receber os mesmos tratamentos. Aos 14 dias de experimento, as dietas não influenciaram a absorção de nitrogênio e a ureia plasmática, porém a dieta ad libitum com a maior porcentagem de lisina reduziu a retenção de nitrogênio. Aos 28 dias, essa mesma dieta aumentou a concentração de ureia plasmática. Conclui-se que o aumento da lisina nas rações melhora o desempenho de suínos machos castrados em terminação, independentemente da forma de arraçoamento, e que a restrição alimentar, nesta fase, não é benéfica.
\end{abstract}

Palavras-chave: metabolismo, nutrição, relação aminoacídica, restrição alimentar

\begin{abstract}
Two experiments were led to evaluate the influence of two percentages of lysine associated to feed restriction over performance and nitrogen balance of finishing barrows. In experiment I, 48 barrows were used, weighing $76.2 \pm 2.3 \mathrm{~kg}$, distributed in a randomized blocks design in factorial scheme $2 \times 2$ (two levels of total lysine - normal or added in $30 \%$ - and two feed programs - restricted or ad libitum). At 28 days, the levels of lysine did not influence weight gain, but the higher level provided lesser feed intake and better feed:gain. The feed restriction decreased the weight gain without affecting feed:gain. In Experiment II, 24 barrows, weighing $74.1 \pm 2.5 \mathrm{~kg}$, were put in metabolic cages to receive the same previously described treatments. At 14 days of the experiment, the diets did not influence the nitrogen absorption and the plasmatic urea, however, the ad libitum diet associated at the higher lysine level reduced nitrogen retention. At 28 days, this same diet increased the plasmatic urea concentration. It was concluded that the increase of lysine levels in diets improves performance in finishing barrows, regardless of the feed program, and feed restriction, in this phase, is not beneficial.
\end{abstract}

Keywords: amino acid ratio, feed restriction, metabolism, nutrition

Recebido em 31 de julho de 2010

Aceito em 9 de setembro de 2011

E-mail: erinalmeida@ig.com.br

Apoio: FAPEMIG 


\section{INTRODUÇÃO}

O surgimento de novas linhagens, aliada à necessidade de abate de suínos mais pesados, com menor tempo de desenvolvimento e melhor qualidade, tem desafiado os nutricionistas a elaborarem dietas mais precisas em termos de exigências nutricionais e menos onerosas ao produtor. Nesse sentido, existem consideráveis diferenças na habilidade de ganhar peso e na eficiência de conversão dos nutrientes em carne, principalmente em suínos em terminação. Assim, faz-se necessário adequar a nutrição e o manejo alimentar para evitar perdas de desempenho nesta fase e propiciar maior deposição de nitrogênio nos tecidos.

A restrição alimentar, nesta fase, pode ser favorável à melhora dos índices zootécnicos, pois é quando os animais apresentam elevada capacidade de consumo, muitas vezes ingerindo quantidades excessivas de ração, acarretando maior deposição de gordura e maior excreção de elementos poluentes pelos dejetos. Nessas circunstâncias a restrição alimentar poderia amenizar tais problemas. Esse procedimento é bastante utilizado pela indústria integradora que busca menor consumo de ração por quilo de carne produzida. De fato, Fabian et al. (2002) observaram melhora na retenção de nitrogênio quando os animais foram submetidos à restrição alimentar. No entanto, isso nem sempre ocorreu, em razão do provável menor aporte de aminoácidos, principalmente lisina, que é o principal limitante para a síntese de proteína muscular. Nesse caso, os demais aminoácidos não utilizados para a síntese proteica seriam direcionados para a deposição de tecido adiposo.

Suínos com elevado potencial genético para produção de carne necessitam de quantidades diárias mais elevadas de lisina em relação aos de baixo e médio potencial para maximizar o desempenho e a taxa de deposição de proteína, principalmente nas fases de crescimento e terminação (Friesen et al., 1995). Além disso, benefícios também podem ser observados com relação à excreção de nitrogênio, que pode ser reduzida quando as dietas são suplementadas com aminoácidos cristalinos e o teor de proteína bruta é reduzido (Zangeronimo et al., 2009).
Assim, o uso de programas de restrição alimentar associado ao aumento dos níveis de lisina pode ser positivo para o melhor aproveitamento do nitrogênio dietético pelos animais. Dessa forma, o objetivo deste trabalho foi avaliar a influência da inclusão de duas porcentagens de lisina, alta e baixa, associada a duas formas de arraçoamento, à vontade ou restrita, sobre o desempenho e o balanço de nitrogênio de suínos em terminação.

\section{MATERIAL E MÉTODOS}

Dois experimentos foram realizados no Setor de Suinocultura do Departamento de Zootecnia da Universidade Federal de Lavras (UFLA), em Lavras, Minas Gerais entre setembro de 2005 e fevereiro de 2006. Para o desempenho - primeiro experimento -, foram utilizados 48 suínos machos castrados, com média de peso inicial de $76,2 \pm 2,3 \mathrm{~kg}$, híbridos de linhagem selecionada para alta deposição de carne magra, procedentes de uma granja comercial. Os animais foram alojados em grupos de dois, em baias de piso parcialmente ripado com dimensão de $2,30 \times 1,5 \mathrm{~m}$, dotadas de comedouro semiautomático e bebedouro tipo chupeta. Água e ração foram fornecidos à vontade. Antes do início do período experimental, os animais permaneceram nas instalações durante 12 dias para adaptação a elas.

O delineamento experimental foi em blocos ao acaso, em arranjo fatorial $2 \times 2$ (duas porcentagens de lisina e duas formas de arraçoamento - à vontade ou restrita), totalizando quatro tratamentos e seis repetições. O período experimental foi de 28 dias. A dieta basal foi formulada à base de milho e farelo de soja para atender às exigências mínimas recomendadas por Rostagno et al. (2005) para suínos machos castrados de alto potencial genético com alto desempenho (Tab. 1). Outra dieta foi formulada para conter $30 \%$ a mais de lisina total, equivalente a $24 \%$ na lisina digestível. Os tratamentos foram: T1 - dieta alta lisina fornecida à vontade; T2 - dieta alta lisina fornecida com $15 \%$ de restrição alimentar; T3 dieta lisina normal fornecida à vontade; T4 dieta lisina normal fornecida com $15 \%$ de restrição alimentar. 
Desempenho e balanço de nitrogênio...

Tabela 1. Composição centesimal e calculada das dietas experimentais fornecidas a suínos em terminação

\begin{tabular}{|c|c|c|c|c|}
\hline Ingrediente (\%) & $\mathrm{T} 1$ & $\mathrm{~T} 2$ & T3 & $\mathrm{T} 4$ \\
\hline Milho & 77,62 & 77,62 & 78,02 & 78,02 \\
\hline Farelo de soja & 19,50 & 19,50 & 19,50 & 19,50 \\
\hline Óleo de soja & 0,65 & 0,65 & 0,50 & 0,50 \\
\hline L-Lisine- $\mathrm{HCl} 78 \%$ & 0,315 & 0,315 & 0,073 & 0,073 \\
\hline Fosfato bicálcico & 0,80 & 0,80 & 0,80 & 0,80 \\
\hline Calcáreo & 0,57 & 0,57 & 0,57 & 0,57 \\
\hline Sal comum & 0,30 & 0,30 & 0,30 & 0,30 \\
\hline Premix mineral $^{1}$ & 0,10 & 0,10 & 0,10 & 0,10 \\
\hline Premix vitamínico ${ }^{2}$ & 0,10 & 0,10 & 0,10 & 0,10 \\
\hline Tylan G-250 & 0,04 & 0,04 & 0,04 & 0,04 \\
\hline Proteína bruta $(\%)$ & 15,53 & 15,53 & 15,53 & 15,53 \\
\hline Energia metabolizável (kcal/kg) & 3261 & 3261 & 3262 & 3262 \\
\hline Lisina total $(\%)$ & 1,17 & 1,17 & 0,90 & 0,90 \\
\hline Lisina digestível (\%) & 1,01 & 1,01 & 0,81 & 0,81 \\
\hline Fósforo disponível (\%) & 0,245 & 0,245 & 0,245 & 0,245 \\
\hline Cálcio $(\%)$ & 0,485 & 0,485 & 0,485 & 0,485 \\
\hline
\end{tabular}

T1: dieta alta lisina fornecida à vontade; T2: dieta alta lisina fornecida com 15\% de restrição alimentar; T3: dieta lisina normal (segundo Rostagno et al., 2005) fornecida à vontade; T4: dieta lisina normal fornecida com $15 \%$ de restrição alimentar.

${ }^{1}$ Composição por kg de produto: cálcio, $98.800 \mathrm{mg}$; cobalto, 185mg; cobre, 15,750mg; ferro, 26.250mg; iodo, $1.470 \mathrm{mg}$; manganês, $41.850 \mathrm{mg}$; zinco, $77.999 \mathrm{mg}$.

${ }^{2}$ Composição por kg de produto: ácido fólico, 116,55mg; ácido pantotênico, 2.333,5mg; biotina, 5,28mg; niacina, 5.600mg; piridoxina, $175 \mathrm{mg}$; riboflavina, $933,3 \mathrm{mg}$; tiamina, $175 \mathrm{mg}$; Vit. A, $1.225 .000 U \mathrm{UI}$; Vit. $\mathrm{D}_{3}$, 315.000UI.; Vit. E, $1.400 \mathrm{mg}$; Vit. $\mathrm{K}_{3}, 700 \mathrm{mg}$; Vit. $\mathrm{B}_{12}, 6.825 \mathrm{mg}$; selênio, $105 \mathrm{mg}$; antioxidante: $1.500 \mathrm{mg}$.

Foram avaliados o consumo diário de ração, o ganho de peso diário, a conversão alimentar e o consumo de lisina. O consumo de ração foi avaliado diariamente, sempre pela manhã, por meio de pesagem do fornecido e das sobras. O cálculo da quantidade de ração diária fornecida aos animais com restrição alimentar foi feito com base no consumo médio total do dia anterior dos animais que receberam ração ad libitum, com a mesma porcentagem de lisina. Para a determinação do ganho de peso, os animais foram pesados no início e no final do experimento. A conversão alimentar foi obtida por meio da relação entre o consumo de ração e o ganho de peso durante o período experimental.

Para o balanço de nitrogênio - segundo experimento -, foram utilizados 24 suínos machos castrados, com média de peso inicial de $74,1 \pm 2,5 \mathrm{~kg}$, da mesma linhagem utilizada no experimento anterior, alojados individualmente em gaiolas metabólicas para coleta de fezes e urina. As gaiolas estavam localizadas em uma sala equipada com ar condicionado, para permitir o controle da temperatura interna em torno de $18^{\circ} \mathrm{C}$. O experimento foi dividido em dois períodos com 12 animais cada, totalizando 24 animais em seis repetições. Cada período teve duração de 28 dias, sendo as coletas de fezes e urina feitas em duas fases: aos 11, 12, 13 e 14 dias e aos 25, 26, 27 e 28 dias de experimento. O delineamento experimental e a composição dos tratamentos foram os mesmos utilizados no ensaio de desempenho.

As rações foram fornecidas às sete, 12 e 17 horas, e a quantidade total diária foi estabelecida com base no peso metabólico $\left(\mathrm{PV}^{0,75}\right)$, ajustando o consumo de todos os animais em função daquele de menor ingestão observado durante a fase de adaptação, de 10 dias. Dessa forma, todos os animais consumiram quantidades iguais de nutrientes em relação ao peso metabólico, exceto os animais submetidos à restrição alimentar, cujo cálculo também foi estabelecido com $15 \%$ de restrição em relação ao consumo indicado.

As rações foram umedecidas na proporção de 2:1 de água:ração. Após o consumo do alimento, todos os animais receberam água à vontade. Para determinar o início e o final do período de coleta de fezes e urina, utilizou-se o óxido férrico $\left(\mathrm{Fe}_{2} \mathrm{O}_{3}\right)$ como marcador fecal, adicionando-se 
$2 \%$ à ração na primeira e na última refeição do período determinado. A urina foi recolhida diariamente, com auxílio de um balde plástico com filtro, contendo $20 \mathrm{~mL}$ de ácido clorídrico (HCl) 1:1 para evitar a proliferação bacteriana e possíveis perdas de nitrogênio.

Foram analisados o teor de matéria seca (com exceção da urina) e nitrogênio total, segundo metodologia descrita por Silva e Queiroz (2002). Para análise de ureia plasmática, o sangue foi coletado às $8 \mathrm{~h}$ da manhã do último dia de cada fase de coleta de fezes e urina - aos 14 e aos 28 dias de experimento. As coletas foram feitas por meio de punção do sinus orbital, e o plasma obtido por centrifugação (1600rpm) das amostras de sangue a $5^{\circ} \mathrm{C}$ por $10 \mathrm{~min}$. Este foi armazenado a $-20^{\circ} \mathrm{C}$ até a análise da concentração de ureia plasmática, que foi determinada por meio de kit enzimático LABTEST (Analisa Diagnóstica Ltda.), usando-se a técnica de colorimetria. Foram avaliadas a absorção e a retenção de nitrogênio (\%), a relação nitrogênio retido:absorvido (valor biológico) e a concentração de ureia plasmática.

Os dados experimentais foram submetidos à análise de variância após o teste de normalidade, sendo as médias de cada fator, isolado ou dentro da interação, comparadas pelo teste F. A análise estatística foi realizada utilizando-se o procedimento GLM do pacote estatístico Statistical... (2001).

\section{RESULTADOS E DISCUSSÃO}

Não se observou interação $(\mathrm{P}>0,05)$ das variáveis de desempenho estudadas. Os níveis de lisina não influenciaram o ganho de peso $(\mathrm{P}>0,05)$, mas seu aumento na ração reduziu o consumo e afetou a conversão alimentar $(\mathrm{P}<0,05)$, independentemente do programa de alimentação utilizado (Tab. 2).

Tabela 2. Desempenho de suínos em terminação alimentados com dietas contendo diferentes porcentagens de lisina, com ou sem restrição alimentar, durante 28 dias

\begin{tabular}{|c|c|c|c|}
\hline \multirow{2}{*}{ Lisina $(\%)$} & \multicolumn{2}{|c|}{ Forma de arraçoamento } & \multirow{2}{*}{ Média } \\
\hline & à vontade & restrita & \\
\hline \multicolumn{4}{|c|}{ Ganho de peso diário (g/dia) } \\
\hline Alto & 1082 & 970 & 1026 \\
\hline Normal & 1095 & 942 & 1019 \\
\hline Média & $1088 \mathrm{a}$ & $956 \mathrm{~b}$ & \\
\hline $\mathrm{CV}(\%)$ & 5,3 & & \\
\hline \multicolumn{4}{|c|}{ Consumo de ração diário $(\mathrm{g} /$ dia $)$} \\
\hline Alto & 3212 & 2820 & $3016 \mathrm{~B}$ \\
\hline Normal & 3310 & 2908 & $3109 \mathrm{~A}$ \\
\hline Média & $3261 \mathrm{a}$ & $2864 \mathrm{~b}$ & \\
\hline $\mathrm{CV}(\%)$ & 3,99 & & \\
\hline \multicolumn{4}{|c|}{ Conversão alimentar $(\mathrm{g} / \mathrm{g})$} \\
\hline Alto & 2,982 & 2,925 & $2,953 \mathrm{~B}$ \\
\hline Normal & 3,038 & 3,113 & $3,075 \mathrm{~A}$ \\
\hline Média & 3,01 & 3,019 & \\
\hline $\mathrm{CV}(\%)$ & 4,18 & & \\
\hline
\end{tabular}

Médias seguidas de diferentes letras minúsculas na linha ou maiúsculas na coluna diferem entre si pelo teste $\mathrm{F}$ $(\mathrm{P}<0,05)$.

Resultados semelhantes ao ganho de peso foram obtidos por Witte et al. (2000) e Oliveira et al. (2003), ao trabalharem com suínos dos 110 aos $125 \mathrm{~kg}$ e 95 aos $110 \mathrm{~kg}$, respectivamente, enquanto Arouca et al. (2004) observaram efeito quadrático da porcentagem de inclusão de lisina sobre o ganho de peso dos animais nessa mesma fase, em que a máxima resposta foi obtida com $0,75 \%$ de lisina total, com animais alimentados ad libitum. Neste caso, os autores variaram os níveis de 0,5 para $0,9 \%$ de lisina total, abaixo do maior nível utilizado no presente experimento. Considerando-se o comportamento observado para esta variável, pode-se inferir que os suínos respondem a quantidades crescentes de lisina na dieta até o limite provavelmente determinado pelo potencial genético. No presente experimento, as porcentagens de lisina estavam acima das recomendadas para a linhagem.

Segundo D’Mello (1993), o não balanceamento de aminoácidos tem como uma das 
consequências a redução no consumo de ração. No presente trabalho, não houve suplementação da dieta com outros aminoácidos, o que pode ter direcionado a lisina para a síntese de lipídios no fígado.

A redução no consumo favoreceu a conversão alimentar no presente trabalho. Para esta variável, Arouca et al. (2005) concluíram que $0,61 \%$ de lisina total é o ideal, ao trabalharem com condições semelhantes à do presente estudo. Esses autores obtiveram valores de 3,23 na conversão em animais dos 96 aos 120kg. Para animais selecionados para alta deposição de carne magra, Arouca et al. (2004) estimaram ser de $0,76 \%$ a lisina total para se obter a conversão alimentar de 3,18. Nos dois experimentos dos autores citados, a porcentagem recomendada está bem abaixo da utilizada no presente experimento, isto é, a porcentagem adequada foi a de $1,17 \%$ de lisina (Tab. 1), para obter conversão de 2,95 (Tab. 2).

Os resultados obtidos neste trabalho confirmam que suínos de elevado potencial para deposição de tecido magro necessitam de maior quantidade de lisina na dieta para expressar sua maior eficiência produtiva. Machos castrados em terminação e com alta capacidade de deposição de carne normalmente consomem menos alimento e são mais eficientes, pois respondem às porcentagens de lisina na dieta (Friesen et al., 1994).

Quanto ao programa alimentar, a restrição prejudicou o desempenho, resultando $(\mathrm{P}<0,05)$ em menor consumo e menor ganho de peso, sem, no entanto, afetar a conversão alimentar ( $\mathrm{P}>0,05)$. Bertol et al. (2001) concluíram que programas de restrição em suínos de alto potencial de deposição de carne aumentam de forma linear o tempo para os animais atingirem idade de abate, provavelmente em razão da falta de outros aminoácidos que não a lisina.

Com relação à absorção de nitrogênio, as porcentagens de inclusão de lisina em programas de restrição não influenciaram esta variável nem aos 14 dias e nem aos 28 dias de experimento (Tab. 3 e 4). Estes resultados mostram que não houve competição entre aminoácidos ao se incluir a lisina na dieta. Segundo Partridge (1985), a presença de aminoácidos cristalinos pode interferir na absorção de outros aminoácidos por competir pelas proteínas de transporte nos enterócitos, alterando a capacidade do animal em absorver estes nutrientes.

Tabela 3. Balanço de nitrogênio e concentração de ureia plasmática de suínos em terminação alimentados com dietas contendo diferentes níveis de lisina, com ou sem restrição alimentar, durante 14 dias

\begin{tabular}{|c|c|c|c|}
\hline \multirow[b]{2}{*}{ Nível de lisina } & \multicolumn{2}{|c|}{ Forma de arraçoamento } & \multirow[b]{2}{*}{ Média } \\
\hline & à vontade & restrita & \\
\hline \multicolumn{4}{|c|}{ Nitrogênio absorvido (\%) } \\
\hline Alto & 90,9 & 91,5 & 91,2 \\
\hline Normal & 91,1 & 91,5 & 91,3 \\
\hline Média & 91,0 & 91,5 & \\
\hline $\mathrm{CV}(\%)$ & 0,96 & & \\
\hline \multicolumn{4}{|c|}{ Nitrogênio retido (\%) } \\
\hline Alto & $65,4 \mathrm{Bb}$ & $70,0 \mathrm{a}$ & 67,7 \\
\hline Normal & $70,8 \mathrm{~A}$ & 69,1 & 69,9 \\
\hline Média & 68,1 & 69,5 & \\
\hline $\mathrm{CV}(\%)$ & 5,22 & & \\
\hline \multicolumn{4}{|c|}{ Nitrogênio retido do absorvido (\%) } \\
\hline Alto & $72,0 \mathrm{Bb}$ & $76,5 \mathrm{a}$ & 74,2 \\
\hline Normal & $77,7 \mathrm{~A}$ & 75,5 & 76,6 \\
\hline Média & 74,9 & 76 & \\
\hline $\mathrm{CV}(\%)$ & 5,21 & & \\
\hline \multicolumn{4}{|c|}{ Ureia plasmática $(\mathrm{mg} / \mathrm{dL})$} \\
\hline Alto & 22,50 & 26,00 & 24,30 \\
\hline Normal & 24,30 & 24,00 & 24,20 \\
\hline Média & 23,40 & 25,00 & \\
\hline $\mathrm{CV}(\%)$ & 12,63 & & \\
\hline
\end{tabular}

Médias seguidas de diferentes letras minúsculas na linha ou maiúsculas na coluna diferem entre si pelo teste $\mathrm{F}$ $(\mathrm{P}<0,05)$. 
Tabela 4. Balanço de nitrogênio e concentração de ureia plasmática de suínos em terminação alimentados com rações contendo diferentes níveis de lisina, com ou sem restrição alimentar, durante 28 dias

\begin{tabular}{|c|c|c|c|}
\hline \multirow[b]{2}{*}{ Nível de lisina } & \multicolumn{2}{|c|}{ Forma de arraçoamento } & \multirow[b]{2}{*}{ Média } \\
\hline & à vontade & restrita & \\
\hline \multicolumn{4}{|c|}{ Nitrogênio absorvido (\%) } \\
\hline Alto & 91,1 & 91,4 & 91,2 \\
\hline Normal & 91,2 & 92,6 & 91,9 \\
\hline Média & 91,0 & 91,5 & \\
\hline $\mathrm{CV}(\%)$ & 1,67 & & \\
\hline \multicolumn{4}{|c|}{ Nitrogênio retido (\%) } \\
\hline Alto & 66,26 & 67,92 & 67,09 \\
\hline Normal & 66,55 & 65,92 & 66,23 \\
\hline Média & 66,4 & 66,92 & \\
\hline $\mathrm{CV}(\%)$ & 3,92 & & \\
\hline \multicolumn{4}{|c|}{ Nitrogênio retido do absorvido (\%) } \\
\hline Alto & 72,76 & 74,38 & 73,57 \\
\hline Normal & 72,95 & 71,19 & 72,07 \\
\hline Média & 72,86 & 72,78 & \\
\hline $\mathrm{CV}(\%)$ & 4,17 & & \\
\hline \multicolumn{4}{|c|}{ Ureia plasmática $(\mathrm{mg} / \mathrm{dL})$} \\
\hline Alto & 26,33 & 21,83 & $24,08 \mathrm{~A}$ \\
\hline Normal & 20,67 & 19,67 & $20,17 \mathrm{~B}$ \\
\hline Média & $23,50 \mathrm{a}$ & $20,75 \mathrm{~b}$ & \\
\hline $\mathrm{CV}(\%)$ & 10,27 & & \\
\hline
\end{tabular}

Médias seguidas de diferentes letras minúsculas na linha ou maiúsculas na coluna diferem entre si pelo teste $\mathrm{F}$ $(\mathrm{P}<0,05)$

Com relação ao nitrogênio retido, houve interação $(\mathrm{P}<0,05)$ de porcentagem de inclusão de lisina versus forma de arraçoamento aos 14 dias de experimento, mas não aos 28 dias. $\mathrm{Na}$ dieta fornecida à vontade e com maior porcentagem de lisina, houve menor $(\mathrm{P}<0,05)$ retenção de nitrogênio, o que reduziu $(\mathrm{P}<0,05)$ o valor biológico da proteína dietética neste período, mostrado pela menor relação nitrogênio retido:absorvido. Isso pode ser atribuído à não suplementação da dieta com aminoácidos cristalinos para manutenção da relação entre os aminoácidos e a lisina da dieta. Outro fato interessante observado é que os níveis de lisina não afetaram $(\mathrm{P}>0,05)$ a retenção de nitrogênio quando as dietas foram administradas de forma restrita até os 14 dias de experimento, mas o aumento deste aminoácido reduziu $(\mathrm{P}<0,05)$ a retenção quando elas foram fornecidas à vontade.

Estes resultados confirmam o direcionamento do excesso de lisina para o metabolismo lipídico descrito anteriormente, estimulando o fígado a produzir maior quantidade de ureia para ser eliminada. No entanto, a concentração desse composto nitrogenado no sangue só se refletiu aos 28 dias de experimento, quando o aumento do nível de lisina propiciou $(\mathrm{P}<0,05)$ maior síntese de ureia pelo organismo com o intuito de eliminar o excesso de nitrogênio. Segundo Cameron et al. (2003), a lisina consumida, além de suprir as necessidades de mantença e de deposição de proteína, é catabolizada, e o nitrogênio resultante desse catabolismo é excretado como ureia.

Essa melhora na retenção de nitrogênio, quando os animais são submetidos à restrição alimentar, pode ser atribuída à indução no aumento da eficiência da síntese proteica pela redução da oxidação e melhor eficiência de utilização dos aminoácidos (Fabian et al., 2002). Considerandose a emissão de elementos poluentes pelos animais por meio dos dejetos, o melhor aproveitamento de nutrientes é vantajoso. No entanto, considerando-se o desempenho dos animais, este mostrou-se inferior em relação àqueles que receberam ração ad libitum.

Diferentemente do que foi observado aos 14 dias do experimento, não houve diferença $(\mathrm{P}>0,05)$ no balanço de nitrogênio aos 28 dias, ou seja, o aumento da lisina ou as formas de fornecimento de ração não influenciaram a capacidade de os animais absorverem e reterem o nitrogênio dietético. Os resultados obtidos nesta fase do 
experimento podem estar relacionados ao fato de todos os animais receberem dietas restritas, principalmente os submetidos ao programa de restrição em 15\%, não repetindo, dessa forma, os resultados obtidos aos 14 dias de experimento.

\section{CONCLUSÕES}

O aumento da lisina nas dietas melhora o desempenho de suínos machos castrados em terminação, independentemente da forma de arraçoamento, mas torna a utilização do nitrogênio menos eficiente. A restrição alimentar de $15 \%$, nesta fase, é traduzida em desempenho mais baixo, apesar de apresentar melhor utilização do nitrogênio e menor excreção desse elemento pelos animais.

\section{REFERÊNCIAS BIBLIOGRÁFICAS}

AROUCA, C.L.C.; FONTES, D.O.; FERREIRA, W.M. et al. Exigências de lisina, com base no conceito de proteína ideal, para suínos machos castrados, de 95 a $122 \mathrm{~kg}$, selecionados para deposição de carne magra. Arq. Bras. Med. Vet. Zootec., v.56, p.773-781, 2004.

AROUCA, C.L.C.; FONTES, D.O.; VELOSO, J.A.F. et al. Exigências de lisina, com base no conceito de proteína ideal, para suínos machos castrados dos 96 aos $120 \mathrm{~kg}$, selecionados para eficiência de crescimento. Arq. Bras. Med. Vet. Zootec., v.57, p.104-111, 2005.

BERTOL, T.M.; LUDKE, J.V.; BELLAVER, C. Efeito do peso do suíno em terminação ao início da restrição alimentar sobre o desempenho e a qualidade de carcaça. Rev. Bras. Zootec., v.30, p.417-424, 2001.

CAMERON, N.D.; McCULLOUGH, E.; TROUP, K. et al. Serum urea concentration as a predictor of dietary lysine requirement in selected lines of pigs. $J$. Anim. Sci., v.81, p.91-100, 2003.

D'MELLO, J.P.F. Amino acid supplementation of cereal-based diets for non-ruminants. Anim. Feed Sci. Technol., v.45, p.1-18, 1993.

FABIAN, J.; CHIBA, L.I.; KUHLERS, D.L. et al. Degree of amino acid restrictions during the grower phase and compensatory growth in pigs selected for lean growth efficiency. J. Anim. Sci., v.80, p.26102618, 2002.
FRIESEN, K.G.; NELSSEN, J.L.; GOODBAND, R.D. et al. Influence of dietary lysine on growth and carcass composition of high-lean-growth gilts fed from 34 to 72 kilograms. J. Anim. Sci., v.72, p.1761-1770, 1994.

FRIESEN, K.G.; NELSSEN, J.L.; GOODBAND, R.D. et al. The effect of dietary lysine on growth, carcass composition, and lipid metabolism in highlean growth gilts fed from 72 to 136 kilograms. J. Anim. Sci., v.73, p.3392- 3401, 1995.

OLIVEIRA, A.L.S.; DONZELE, J.L.; OLIVEIRA, R.F.M. et al. Lisina em rações para suínos machos castrados selecionados para deposição de carne magra na carcaça dos 95 aos 110kg. Rev. Bras. Zootec., v.32, p.337-343, 2003.

PARTRIDGE, I.G.; LOW, A.G.; KEAL, H.D. A note on the effect of feeding frequency on nitrogen use in growing boars given diets with varying levels of free lysine. Anim. Prod., v.40, p.375-377, 1985.

ROSTAGNO, H.S.; ALBINO, L.F.T.; DONZELE, J.L. et al. Tabelas brasileiras para suínos e aves: composição de alimentos e exigências nutricionais. 2.ed. Viçosa: UFV, 2005. 186p.

SILVA, D.J.; QUEIROZ, A.C. Análises de alimentos: métodos químicos e biológicos. Viçosa: UFV, 2002. 235p.

STATISTICAL Analyses System - SAS. System for Microsoft Windows Release 8.2, Cary: CD ROM, 2001.

WITTE, D.P.; ELLIS, M.; McKEITH, F.K. et al. Effect of dietary lysine and environmental temperature during the finishing phase on the intramuscular fat content of pork. J. Anim. Sci., v.78, p.1272-1276, 2000.

ZANGERONIMO, M.G.; FIALHO E.T.; LIMA, J.A.F. et al. Performance and carcass characteristics of swine from 20 to $50 \mathrm{~kg}$ receiving diets with reduced crude protein and different levels of true digestible lysine. Cienc. Rural., v.39, p. 1507-1513, 2009. 